\title{
Kajian Literatur Pengaruh Model Learning Cycle terhadap Hasil Belajar Tematik Terpadu
}

\author{
Selviana Sasmiati Nur ${ }^{1 凶}$, Iska Noviardila ${ }^{2}$ \\ (1) Pendidikan Guru Sekolah Dasar, Universitas Pahlawan Tuanku Tambusai \\ (2) Pendidikan Jasmani dan Kesehatan, Universitas Pahlawan Tuanku Tambusai
}

$\square$ Corresponding author

[selvianasasmiatinur07@gmail.com]

\begin{abstract}
Abstrak
Penelitian ini dilatarbelakangi oleh rendahnya hasil belajar siswa sekolah dasar. Tujuan penelitian ini untuk mengetahui pengaruh model Learning cycle terhadap hasil belajar tematik terpadu. Metode penelitian ini adalah metode penelitian kajian literature. Tahapan kajian literature ini adalah pengumpulan data, reduksi data, display data, pembahasan, dan kesimpulan. Hasil penelitian menunjukkan bahwa dari 6 artikel dari tahun 2010-2020 tentang model Learning Cycle dan hasil belajar didapat 1 artikel yang sesuai dengan judul. Berdasarkan hasil penelitian tersebut yang dilakukan peneliti tentang pengaruh model Learning Cycle terhadap hasil belajar tematik terpadu disekolah dasar, didapat peningkatan hasil perhitungan thitung sebesar 9,46 dan nilai ttabel dengan taraf signifikasi $1 \%$ adalah 2,44 . thitung $\geq$ ttabel, atau $9,46 \geq 2,44$. Maka dapat disimpulkan model learning cycle dapat meningkatkan hasil belajar tematik terpadu disekolah dasar.
\end{abstract}

Kata Kunci: Literatur; Learning Cycle; Hasil Belajar

\begin{abstract}
This research is motivated by the low learning outcomes of elementary school students. The purpose of this study was to determine the effect of the Learning cycle model on integrated thematic learning outcomes. This research method is a literature review research method. The stages of this literature review are data collection, data reduction, data display, discussion, and conclusions. The results showed that from 6 articles from 2010-2020 about the Learning Cycle model and learning outcomes, 1 article was found in accordance with the title. Based on the results of the research conducted by researchers on the effect of the Learning Cycle model on integrated thematic learning outcomes in elementary schools, an increase in the calculation of tcount was 9.46 and the $t$-table value with a significance level of $1 \%$ was 2.44 . tcount $\geq$ ttable, or $9.46 \geq$ 2.44. So it can be concluded that the learning cycle model can improve integrated thematic learning outcomes in elementary schools.
\end{abstract}

Keyword: Visionary Leadership; Teacher Discipline; Teacher Performance

\section{PENDAHULUAN}

Pendidikan mempunyai peranan sangat penting yang harus dimiliki oleh seseorang dalam menjalani kehidupannya, salah satunya memberikan pengetahuan pada setiap individu dalam rangka mencerdaskan kehidupan bangsa. Pendidikan dapat melahirkan manusia yang kreatif , dan memiliki ide yang cemerlang sebagai bekal untuk memperoleh masa depan yang baik. Hal ini sesuai dengan Undang-undang No 20 Tahun 2003 tentang Sistem Pendidikan Nasional pasal 1 ayat 1 yang menjelaskan bahwa, pendidikan merupakan suatu usaha sadar dan terencana untuk mewujudkan suasana belajar dan proses pembelajaran agar peserta didik secara aktif mengembangkan potensi dirinya untuk memiliki kekuatan spiritual keagaamaan, pengendalian diri, kepribadian, kecerdasan, akhlak mulia, serta keterampilan yang diperlukan darinya, masyarakat, bangsa dan negara.

Arikunto (2010) menyatakan bahwa pendidikan bagi bangsa yang sedang membangun seperti bangsa Indonesia saat ini merupakan kebutuhan mutlak yang harus dikembangkan sejalan dengan tuntutan pembangunan secara tahap demi tahap. Pendidikan yang dikelola dengan tertib, teratur, efektif dan efisien (berdaya guna dan berhasil guna) akan mampu mempercepat jalannya proses pembudayaan bangsa yang berdasarkan pokok pada penciptaan kesejahteraan umum dan pencerdasan kehidupan bangsa.

Pendidikan akan terlaksana dengan baik apabila adanya sebuah pedoman dalam pelaksanaannya. Pedoman yang diperlukan dalam pelaksanaan pendidikan adalah kurikulum, karena didalam kurikulum berisi acuan sebagai tuntutan dalam pelaksanaan pendidikan. Pada dasarnya kurikulum berpusat pada potensi, perkembangan, kebutuhan dan kepentingan peserta didik serta lingkungannya yang dikembangkan berdasarkan prinsip bahwa peserta didik berada dalam posisi sentral dan aktif dalam belajar. 
Pemerintah terus melakukan kemajuan sistem pendidikan nasional salah satunya penyempurnaan kurikulum. Sesuai dengan Peraturan Menteri Pendidikan dan Kebudayaan Republik Indonesia Nomor 81 A Tahun 2013 tentang implementasi kurikulum dinyatakan bahwa tahun pelajaran 2013/2014 diberlakukan kurikulum baru yaitu kurikulum 2013 secara bertahap.

Proses pembelajaran Kurikulum 2013 dilakukan secara terpadu, berdasarkan pada tema dan kemudian dikaitkan antara mata pelajaran yang satu dengan yang lain. Pembelajaran pada kurikulum 2013 peserta didik dituntut lebih aktif sehingga pendidik hanya berperan sebagai fasilitator dan pembelajaran berpusat pada peserta didik bukan pada pendidik. Diharapkan mampu menghasilkan peserta didik yang memiliki keseimbangan soft skill dan hard skill yang meliputi aspek kompetensi kognitif, afektif, dan psikomotorik agar dapat meningkatkan hasil belajar peserta didik.

Pembelajaran dapat dikatakan efektif dan optimal apabila tujuan pembelajaran dapat tercapai. Demi mencapai tujuan pembelajaran, seorang pendidik dapat menciptakan situasi dan kondisi belajar yang baik dengan cara efektif. Pendidik dituntut untuk bisa menguasai dan menerapkan cara atau model mengajar efektif dan berinovasi yang dapat meningkatkan hasil belajar peserta didik dalam proses pembelajaran.

Hamalik (2013:78) mengemukakan bahwa "pendidik yang baik bukan saja harus menguasai spesialisasi ilmunya akan tetapi harus mengenal proses belajar mengajar, cara-cara mengajar, penggunaan alat-alat mengajar, teknik penilaian, dan sebagainya". Jadi, dalam proses pembelajaran pendidik bukan hanya mempersoalkan apa yang dipelajari saja melainkan juga bagaimana cara pendidik mengajar, bagaimana peserta didik belajar, motif yang mendorongnya untuk belajar, faktor yang mempengaruhi kegiatan belajar sehingga peserta didik akan mengembangkan dirinya dalam seluruh dimensi kepribadiannya.

Proses pembelajaran sangat erat kaitannya dengan hasil belajar. Hasil belajar dapat menunjukkan tingkat keberhasilan proses pembelajaran. Dengan diketahui hasil belajar peserta didik juga membantu pendidik dalam merancang strategi model pembelajaran yang digunakan oleh pendidik dapat berpengaruh pada peserta didik dalam menerima dan menguasai pelajaran. Pemilihan model pembelajaran yang tepat dapat membantu peserta didik untuk memahami dan menguasai materi yang akan dipelajari. Nilai hasil belajar peserta didik dapat digunakan sebagai parameter untuk menilai keberhasilan proses kegiatan pembelajaran disekolah dan juga dapat diukur dalam melaksakasanakan Proses Belajar Mengajar (PBM).

Dalam penelitian ini, model pembelajaran yang digunakan adalah yang dapat merangsang peserta didik untuk berpartisipasi, dan pendidik sebagai fasilitator. Salah satu model yang dapat digunakan untuk meningkatkan hasil belajar adalah model pembelajaran Learning cycle. Model Learning cycle merupakan model pembelajaran berbasis kontruktivisme, yang kegiatan pembelajarannya diorientasikan pada kegiatan peserta didik. Pendekatan kontruktivisme merupakan pandangan pembelajaran yang membelajarkan peserta didik untuk mengkontruksi atau membangun pengetahuannya sendiri melalui skemata yang telah peserta didik miliki sebelumnya.

Pada mulanya model ini terdiri atas tiga tahap, yaitu: eksplorasi (exploration), menjelaskan (explanation), dan memperluas (elaboration/extention), yang dikenal dengan learning cycle 3 E. Pada proses selanjutnya, tiga tahap siklus tersebut mengalami perkembangan menjadi lima tahap, yaitu: keterlibatan (engagement), eksplorasi/menyelidiki (exploration), menjelaskan (explanation), memperluas (elaboration/extention), dan evaluasi (evaluation), sehingga dikenal dengan learning cycle $5 \mathrm{E}$.

Disamping Learning cycle $5 \mathrm{E}$, berdasarkan pengembangan Arthur Einsexraft (2003) mengembangkan siklus belajar menjadi 7 tahapan. Perubahan yang terjadi pada tahapan siklus belajar ( $5 \mathrm{E}$ ) menjadi (7 E) terjadi pada fase Engage menjadi dua tahapan yaitu Elicit dan Engage, sedangkan pada tahap Elaborate dan Evaluate menjadi tiga tahapan yaitu Elaborate, Evaluate, dan Extend.

Model pembelajaran Learning cycle ini memiliki kelebihan merangsang peserta didik mengingat materi sebelumnya untuk mengaitkan dengan materi yang akan di pelajari serta mampu menyampaikan konsep secara lisan. Model ini juga memberikan waktu untuk peserta didik berpikir, mencari, menemukan dan menjelaskan contoh penerapan yang mereka pelajari. Cocok untuk digunakan pendidik agar peserta didik mampu mendalami, memahami dan meningkatkan pengetahuannya. Oleh karena itu, judul dari penelitian ini adalah "Kajian Literatur Pengaruh Model Learning cycle Terhadap Hasil Belajar Tematik Terpadu”.

\section{METODE PENELITIAN}

Kajian literature artikel ilmiah ini dilakukan dirumah dan di perpustakaan daerah. Setiap artikel yang dibaca dalam satu harinya satu artikel, satu artikel dibaca selama dua bahkan tiga jam sampai pada bulan September 2020. Sumber data penelitian ini adalah artikel-artikel ilmiah yang terbit dijurnal nasional dalam waktu 10 tahun terakhir (2011-2020).

Penelitian kepustakaan (library research), yaitu serangkaian penelitian yang berkenaan dengan metode pengumpulan data pustaka, atau penelitian yang obyek penelitiannya digali melalui beragam informasi kepustakaan berupa artikel ilmiah nasional yang dari tahun 2011-2020. Kajian literatur ini bertujuan melakukan telaah pustaka untuk menemukan penelitian terdahulu yang ada hubungan dengan penelitian. Menemukan hasil penelitian lain yang terkait dengan variabel utama atau kunci dalam penelitian 
yang dilaksanakan Syaukani (2017). Sumber literature utama bisa berupa buku-buku referensi dan jurnal ilmiah hasil penelitian yang sebisa mungkin terbitan kurang dari 10 tahun berselang. Dalam usulan dan laporan hasil penelitian, perlu diterangkan penelitian-penelitian lain yang relevan. Selain itu diterangkan pula aspek yang membedakan penelitian-penelitianitu dengan penelitian anda.

Alasan mengapa dipilih strategi Kajian Literatur Artikel IImiah karena sekolah yang tidak dibuka dikarenakan Pandemic Global yaitu Covid-19, sehingga peneliti kesulitan untuk mencari data lapangan secara langsung. Metode penelitian yang digunakan dalam penelitian ini adalah studi kepustakaan. Studi kepustakaan merupakan studi yang digunakan dalam mengumpulkan informasi dan data dengan bantuan berbagai macam material yang ada diperpustakaan seperti dokumen, buku- buku, majalah, sejarah, dll Mirzaqon (2017).

\section{HASIL DAN PEMBAHASAN}

Penelitian kajian pustaka merupakan satu langkah awal yang dilakukan oleh peneliti dalam penyusunan sebuah rencana penelitian yang akan digunakan untuk menelusuri teori-teori atau pendapat para ahli yang berkaitan dengan topik yang akan diteliti. Teori-teori ini bisa didapatkan dari buku, jurnal, terbitanterbitan yang terkait dengan topik pembahasan. Kajian pustaka ini bukan hanya sebagian landasan teori, akan tetapi juga bisa dijadikan referensi untuk menghasilkan sebuah penelitian baru yang mana akan diberikan suatu hal yang berbeda dengan hasil penelitian sebelumnya.

Dalam penelitian ini, peneliti membahas hasil penelitian yang dilakukan oleh peneliti-peneliti sebelumnya yang terkait tentang pengaruh Model Learning cycle terhadap hasil belajar tematik terpadu. Peneliti mengacu pada artikel-artikel yang sudah di display. Display data terdapat 6 artikel yang sesuai dengan judul berdasarkan hasil-hasil penelitian yang dilakukan sebelumnya dan diterbitkan dijurnal nasional pada tahun 2011-2020.

Metode yang digunakan dalam penelitian ini adalah penelitian quasi eksperimental dengan menggunakan desain Control Group Design. Desain ini adalah desain yang didalamnya terdapat dua kelompok Kemudian diberi pretest dan setelah perlakuan selanjutnya diberi postest untuk mengetahui adakah pengaruh antara kelas IV.a yang menggunakan model pembelajaran learning cycle 7e dan kelas IV.b yang menggunakan pembelajaran konvensional.

Hasil penelitian ini menunjukkan bahwa berdasarkan hasil analisis uji statistik dan pembahasan maka dapat disimpulkan sebagai berikut : (1) hasil uji hipotesis diperoleh thitung $>$ ttabel atau 9,46 > 2,44, maka dapat disimpulkan bahwa hipotesis penelitian yang menyatakan bahwa terdapat pengaruh hasil belajar antara kelas yang menggunakan model pembelajaran learning cycle 7e dengan kelas yang menggunakan model konvensional setelah perlakuan memperoleh hasil yang lebih tinggi, dan model pebelajaran learning cycle 7e lebih baik digunakan dalam proses pembelajaran. (2) hasil belajar siswa pada ranah sikap menunjukkan bahwa nilai hasil belajar siswa di kelas IV.a yang menggunakan model pembelajaran learning cycle 7e lebih baik dari pada kelas yang menggunakan model konvensional, dengan nilai rata-rata kelas IV.a adalah 3,69 dengan predikat sangat baik dan rata-rata nilai IV.b adalah 2,9 dengan predikat baik. (3) hasil belajar siswa pada ranah keterampilan menunjukkan bahwa nilai hasil belajar siswa di kelas IV.a yang menggunakan model pembelajaran learning cycle 7e lebih baik dari pada kelas yang menggunakan model konvensional, dengan nilai rata-rata kelas eksperimen adalah 3,70 dengan predikat sangat baik dan rata-rata nilai kontrol adalah 2,08 dengan predikat cukup.

\section{Pembahasan}

Pembelajaran learning cycle memberikan kesempatan kepada siswa untuk mengasimilasi informasi dengan cara mengeksplorasi lingkungan, mengakomodasi informasi dengan cara mengembangkan sebuah konsep, mengorganisasikan informasi dan menghubungkan konsep-konsep baru dengan menggunakan atau memperluas konsep yang dimiliki untuk menjelaskan suatu fenomena yang berbeda. Fase engagement dalam learning cycle termasuk dalam proses asimilasi, sedangkan fase evaluation masih merupakan proses akomodasi dan ekuilibrasi. Menurut Eisenkraft (2003) bahwa: "Model pembelajaran learning cycle 7E bertujuan untuk menekankan pentingnya memunculkan pemahaman awal atau pemberian apersepsi kepada siswa dan memperluas (transfer) konsep". Learning cycle 7E mempunyai 7 fase yaitu: (1) elicit (membangun pengetahuan awal siswa), (2) engage (melibatkan atau menarik perhatian siswa), (3) explore (menyelidiki), (4) explain (menjelaskan), (5) elaborate (menerapkan), (6) evaluate (menilai), dan (7) extend (memperluas).

\section{Analisis Artikel Tentang Model Learning Cycle}

Model learning cycle memiliki beberapa fase yang Pada mulanya model ini terdiri atas tiga tahap, yaitu: eksplorasi (exploration), menjelaskan (explanation), dan memperluas (elaboration/extention), yang dikenal dengan learning cycle $3 \mathrm{E}$. Pada proses selanjutnya, tiga tahap siklus tersebut mengalami perkembangan menjadi lima tahap, yaitu: keterlibatan (engagement), eksplorasi/menyelidiki (exploration), 
menjelaskan (explanation), memperluas (elaboration/extention), dan evaluasi (evaluation), sehingga dikenal dengan learning cycle $5 \mathrm{E}$.

Disamping Learning cycle $5 \mathrm{E}$, berdasarkan pengembangan Arthur Einsexraft (2003) mengembangkan siklus belajar menjadi 7 tahapan. Perubahan yang terjadi pada tahapan siklus belajar (5 E) menjadi (7 E) terjadi pada fase Engage menjadi dua tahapan yaitu Elicit dan Engage, sedangkan pada tahap Elaborate dan Evaluate menjadi tiga tahapan yaitu Elaborate, Evaluate, dan Extend. Artinya setiap artikel tentang model Learning Cycle memiliki fase-fase yang berbeda-beda dan disesuaikan dengan materi, permasalahan serta situasi tempat penelitian.

\section{Analisis Artikel Tentang Hasil Belajar}

Dari berbagai pengalaman belajar yang telah diperoleh oleh peserta didik, maka peserta didik akan mendapat hasil belajar yang berupa perubahan tingkah laku dan memperoleh kemampuan-kemampuan. Menurut Sudjana (2019) hasil belajar mencakup kemampuan kognitif, afektif, dan psikomotoris yang masingmasing terdiri dari beberapa tipe mulai dari yang paling rendah sampai yang paling kompleks.

Dari pengertian hasil belajar tersebut, dapat disimpulkan bahwa hasil belajar adalah perubahanperubahan tingkah laku peserta didik yang berupa perubahan pola-pola, perbuatan, nilai-nilai, pengertianpengertian, sikap-sikap, apresiasi, dan keterampilan-keterampilan serta kemampuan-kemampuan kognitif, afektif, dan psikomotoriknya sebagai hasil dari pengalaman belajarnya yang dapat diamati dan diukur yang dapat dinyatakan secara kualitatif (pernyataan-pernyataan) dan kuantitatif (angka-angka). Hasil belajar yang dapat dinyatakan dengan angka misalnya nilai ulangan peserta didik, sementara hasil belajar yang dapat dinyatakan dengan kata-kata misalnya tentang bagaimana sikap peserta didik dalam mengikuti proses pembelajaran, ketrampilan-ketrampilan yang diamati kaitannya dengan proses pembelajaran.

\section{SIMPULAN}

Hasil belajar siswa dapat meningkat dengan menggunakan model learning cycle di sekolah dasar sehingga permasalahan yang terjadi dapat teratasi.Hasil belajar siswa sekolah dasar bias meningkat dengan menggunakan model learning cyclel sehingga tujuan dari pembelajaran tematik di sekolah dasar dapat terlaksana dengan baik.

\section{UCAPAN TERIMA KASIH}

Terima kasih yang sebesar-besarnya kami ucapkan kepada kedua orang tua, dosen pembimbing dan teman-teman yang banyak membantu kami dalam menyelesaikan proyek ini dalam jangka waktu yang terbatas.

\section{DAFTAR PUSTAKA}

Ariant, A. (2012). Definisi Kognitif, Afektif dan Psikomotor.

Arikunto, S. (2010). Prosedur Penelitian Pendidikan Suatu Pendekatan Praktik. Jakarta: Rineka Cipta.

Aris, (2014). Model Pembelajaran Learning Cycle.

Diana, A., Sofiyan, S., Putra, A., \& Ramadhani, D. (2019). Pengaruh Model Pembelajaran Learning Cycle 7e Terhadap Hasil Belajar Siswa pada Tema 6 "Aku dan Cita-Citaku" SD Negeri 6 Langsa. Journal of Basic Education Studies.

Eisenkraft, Arthur. 2003. Expanding the 5E " A Proposed 7E Model emphasize " transfer of learning " and the importance of eliciting prior Understanding. National Science Teacher Association (NSTA). The Science Teacher.

Fajaroh, F. \& Dasna, I W. 2008. Pembelajaran Dengan Model Siklus Belajar (learning cycle). Artikel. Jurusan Kimia FMIPA UM. Tersedia di http://lubisgrafura.wordpress.com/2007/09/20/pembelajarandengan- model-siklus-belajar-learning-cycle/.

Hamalik, O. (2013). Klasifikasi Aktivitas Belajar. hal 78.

Lorbach.(2009).https://www.academia.edu/6942549/Model_Pembelajaran_Learning_Cycle.

Marzali, A. (2016). Menulis kajian literatur. Jurnal Etnosia.

Mecit, Ozlem. 2006. The Effect of 7E Learning cycle Model on The Improvement of Fifth Grade Students Critial Thinking Skills. Tesis.

Mirzaqon, A, Dan Purwako, B. 2017. Studi Kepustakaan Mengenai Landasan Teori Dan Praktik Konseling Expressive Writing. Jurnal Mahasiswa Unesa.

Ngalimun. 2014. Strategi dan Model Pembelajaran. Yogyakarta: Aswaja Presindo.

Pinto,L.E. dkk. 2014. Strategi Pengajaran. Jakaerta: Indeks.

Pribadi, B. A. (2009). Model desain sistem pembelajaran. Jakarta: Dian Rakyat. 
Rusman, R. (2015). Pembelajaran Tematik Terpadu. Jakarta: Raja Grafindo Persada.

Sudjana, N. (2019). Penilaian hasil proses belajar mengajar. (Remaja Rosda Karya, Ed.). Bandung.

Sugiyono (2011), Metode Penelitian Kombinasi (Mixed Methods). Bandung: Alfabeta.

Sugiyono, D. (2017). Metode penelitian kuantitatif kualitatif dan R dan D. Alfabeta: Bandung.

Sugiyono. 2018. Metode Penelitian Pendidikan. Bandung. Alfabeta.

Suprijono, A. (2013). Pembelajaran Kooperatif: Teori \&Aplikasi PAIKEM. Yogyakarta: Pustaka Pelajar.

Susanto, Ahmad. 2016. Teori Belajar dan Pembelajaran di Sekolah Dasar. Jakarta : Kencana.

Syaukani, Metode Penelitian Pedoman Praktis Penelitian Dalam Bidang Pendidikan, (Medan: Perdana Publishing, 2017), HIm. 42-44.

Warsita, B. (2008). Teknologi pembelajaran landasan dan aplikasinya. Jakarta: Rineka Cipta. 